\title{
SOSIALISASI POTENSI LOKAL ACEH BARAT MELALUI PEMANFAATAN ALGA COKELAT (Sargassum sp) KEPADA MASYARAKAT PESISIR DI PANTAI LHOK BUBON ACEH BARAT
}

\section{THE SOCIALIZATION OF WEST ACEH LOCAL POTENCY THROUGH THE UTILIZATION OF BROWN ALGA (Sargassum sp) TO COASTAL COMMUNITY AT LHOK BUBON BEACH WEST ACEH}

\author{
Mohamad Gazali ${ }^{1}$, Zuriat $^{2}$ \\ ${ }_{1}^{1}$ Program Studi IImu Kelautan Fakultas Perikanan dan IImu Kelautan Universitas Teuku Umar \\ ${ }^{2}$ Program Studi Perikanan Fakultas Perikanan dan IImu Kelautan Universitas Teuku Umar \\ Korespondensi : mohamadgazali@utu.ac.id
}

\begin{abstract}
ABSTRAK
Indonesia merupakan suatu negara kepulauan terbesar yang memiliki keanekaragaman hayati laut yang besar. Salah satu keanekaragaman hayati laut yang memilih prospek masa depan yang cerah adalah makroalga laut. makroalga laut tersebar luas di kawasan pesisir Indonesia khususnya wilayah pesisir Barat Selatan Aceh. Makroalga laut terdiri dari 3 kelas yaitu kelas Rhodophyta, Phaeophyta dan Chlorophyta. Salah satu makroalga laut yang memiliki nilai ekonomis penting di wilayah pesisir Barat Selatan Aceh adalah alga cokelat (Sargassum sp). Namun, pemanfaatan alga cokelat (Sargassum sp) belum optimal. Hal ini disebabkan oleh kurang pengetahuan dan keterampilan terkait pengolahan makroalga laut. Oleh karena itu, peneliti melaksanakan kegiatan pengabdian kepada masyarakat di kawasan pesisir Lhok Bubon Aceh Barat. Metode pelaksanaan kegiatan pengabdian kepada masyarakat meliputi kegiatan survey lokasi alga cokelat, sosialisasi pemanfaatan alga cokelat dan pembentukan kelompok masyarakat pesisir. Hasil yang dicapai dalam pelaksanaan kegiatan pengabdian kepada masyarakat ini adalah adanya peningkatan pengetahuan dan keterampilan masyarakat pesisir. Pelaksanaan kegiatan pengabdian kepada masyarakat disambut baik oleh masyarakat pesisir Lhok Bubon. Harapan mereka adalah bagaimana mengolah alga cokelat ini agar dapat memberikan nilai tambah (Value added) bagi kesejahteraan masyarakat pesisir.
\end{abstract}

Kata kunci : Alga cokelat, Pemanfaatan, Sargassum sp, Aceh Barat

\begin{abstract}
Indonesia is the biggest archipelago state that have high marine biodiversity. One of the marine biodiversity that have bright prospect in the future are marine macroalgae. Marine macroalgae have distributed widely in the coastal area of Indonesia especially West South Aceh. Marine macroalga have distributed in the West South Aceh. Marine macroalgae are consist of three classes namely Rhodophyta, Phaeophyta dan Chlorophyta classes. One of the marine macroalgae that have important economical value is brown algae (Sargassum sp). However, the utilization of brown algae (Sargassum sp) has not yet optimal. It is caused by lack of knowledge and skill related marine macroalgae processing. Therefore, the researcher has conducted the activity of empowering community at Lhok Bubon Coastal area. The conducting method of the activity of empowering community including survey of brown alga's site, the socialization of brown alga utilization and forming the coastal community group. The result that reached in conducting empowering community was the enhanching of knowledge and skill of coastal community. The conducting of empowering community were acknowledged by coastal community of Lhok Bubon. Their hope are how to process the brown alga in order to give value added for local community prosperity.
\end{abstract}

Keywords : Brown Alga, Utilization, Sargassum sp, West Aceh 


\section{PENDAHULUAN}

Indonesia memiliki sumberdaya yang cukup besar, baik yang alami maupun yang dibudidayakan. Salah satu sumberdaya yang memiliki potensi yang cukup besar adalah rumput laut. Potensi makroalga laut di Indonesia mempunyai prospek yang cukup cerah karena diperkirakan terdapat 555 spesies makroalga laut yang tersebar di perairan Indonesia dengan total luas lahan perairan yang dapat dimanfaatkan sebesar 1,2 juta hektar (Nindyaning, 2007).

Makroalga laut merupakan salah satu komoditas ekspor yang potensial untuk dikembangkan. Saat ini Indonesia masih merupakan eksportir penting di Asia. Sayangnya algayang banyak diekspor masih berupa bahan mentah yaitu berupa algakering, sedangkan hasil olahan algamasih banyak diimpor dengan nilai yang cukup besar (Anonim, 2003). Makroalga laut akan memiliki nilai jual yang lebih tinggi seandainya diolah menjadi produk intermediet (agar-agar, karaginan, dan alginat) dan produk pangan siap konsumsi (Yorita, 2010). Makroalga laut merupakan kelompok tumbuhan yang berklorofil yang terdiri dari satu atau banyak sel dan berbentuk koloni apabila ditinjau secara biologi. Makroalga laut mengandung bahan-bahan organic seperti polisakarida, hormone, vitamin, mineral dan juga senyawa bioaktif (Putra, 2006).

Pada umumnya, makroalga laut dikelompokkan menjadi empat kelas, yaitu alga hijau (Chlorophyceae), alga hijau biru (Cyanophyceae), alga coklat (Phaeophyceae), dan alga merah (Rhodophyceae) (Winarno 1996). Beberapa jenis algayang bernilai ekonomi tinggi adalah dari golongan Rhodophyceae (ganggang merah) dan Phaeophyceaea (ganggang coklat). Rhodophyceae merupakan algapenghasil agaragar dan karaginan, sedangkan Phaeophyceaea merupakan alga coklat yang belum dioptimalkan pemanfaatannya (Permana, 2008). Alga coklat sering dianggap sebagai sampah karena mengotori pantai, padahal banyak manfaat yang dapat diambil dari algacoklat tersebut. Pemanfaatan alga coklat dalam bidang industri sangat luas, diantaranya untuk industri makanan, minuman, obat-obatan, kosmetik, kertas, detergen, cat, tekstil, vernis, fotografi, dan lain-lain.

Selain di bidang industri, pemanfaatan alga coklat untuk pengobatan sudah dikenal sejak lama. Di Vietnam bagian selatan hingga tengah seperti Khanh Hoa, Quang Nam, Quang Ngai, Binh Dinh, dan lain-lain orang telah memanfaatkan Sargassum dan Porphyra sebagai minuman teh yang berkhasiat medis. Pemanfaatan teh Sargassum oleh masyarakat Vietnam ini telah dilakukan sejak lama (Susanto 2009). Olahan algacoklat berupa teh bias disajikan dengan dicelup (seperti teh celup), serbuk (powder), instan dalam kemasan gelas (Anonim, 2010). Lain halnya di Indonesia, air rebusan algaatau algayang digerus digunakan sebagai obat luar yaitu obat antiseptic dan pemeliharaan kulit. Selain itu, air rebusan dari Sargassum sp. dapat digunakan untuk penyakit gondongan dan penyakit urinari (Yunizal 2004). Novaczek dan Athy (2001) menyatakan dalam bukunya bahwa Sargassum dapat dibuat sebagai minuman sejenis slimming tea yang direkomendasikan bagi seseorang yang memiliki kelebihan berat badan dan ingin mencoba menurunkan berat badannya.

Gazali et al., (2018) menjelaskan bahwa alga cokelat (Sargassum sp) memiliki kandungan senyawa bioaktif yang berkorelasi dengan aktivitas antioksidan. Hal ini terbukti pada nilai $\mathrm{IC}_{50}$ pada alga cokelat (Sargassum $\mathrm{sp}$ ). Pesisir Aceh Barat memiliki potensi sumberdaya kelautan yang begitu pesat seperti algacokelat (Sargassum sp) yang memiliki kandungan senyawa bioaktif yang berguna bagi kesehatan tubuh. Hal ini 
menjadi peluang besar bagi masyarakat pesisir untuk meningkatkan pendapatannya melalui pemanfaatan alga cokelat (Sargassum sp) yang ada di pesisir Barat Aceh.

\section{Permasalahan}

Pesisir Barat Selatan Aceh memiliki keanekaragaman hayati laut yang menjanjikan meliputi terumbu karang, spons, mangrove, padang lamun (seagrasses), gurita, ikan, algadan spesies biota laut lainnya. Namun, pemanfaatan keanekaragaman hayati laut tersebut belum dikelola secara berkelanjutan (sustainable). Hal ini tidak terlepas dari peranan Perguruan Tinggi yang berdekatan langsung dengan pesisir Barat Selatan Aceh untuk mewujudkan Tridharma Perguruan Tinggi yakni pendidikan dan pengajaran, penelitian dan pengabdian kepada masyarakat. Permasalahan utama yang dihadapi mitra Pengabdian Berbasis Riset (PBR) adalah minimnya pemahaman dan pengetahuan tentang pemanfaatan alga cokelat (Sargassum $\mathrm{sp}$ ) sebagai teh alami. Hal ini menjadi inisiatif penulis untuk mencari solusi alternatif.

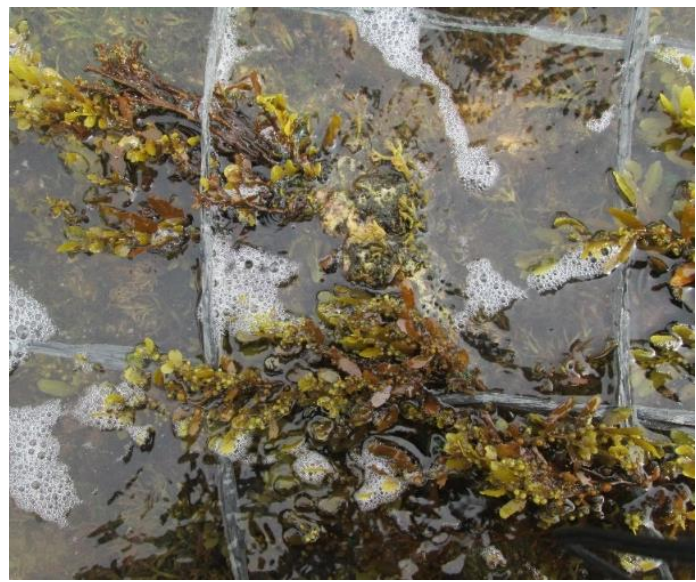

Gambar 1. Potensi alga cokelat asal pesisir Aceh Barat

Permasalahan prioritas yang dihadapi masyarakat pesisir Lhok Bubon Aceh Barat adalah rendahnya pemahaman tentang potensi pemanfaatan alga cokelat (Sargassum sp) sebagai teh alami yang memberikan nilai tambah (Value Added) bagi masyarakat pesisir Aceh Barat. Pesisir Lhok Bubon merupakan kawasan wisata pantai yang banyak diminati masyarakat lokal sehingga tumbuhlah usaha kecil menengah yang memanfaatkan situasi ini melalui café yang menyajikan berbagai jenis menu makanan dan minuman. Pemanfaatan alga cokelat ini (Sargassum sp) belum dilakukan oleh masyarakat pesisir Lhok Bubon.

\section{Tujuan Pelaksanaan}

Tujuan pelaksanaan kegiatan pengabdian kepada masyarakat ini adalah sebagai berikut :

1. Memberikan pemahaman dan pengetahuan kepada masyarakat pesisir Lhok Bubon terkait pemanfaatan algacokelat (Sargassum sp) sebagai teh alami.

2. Membangun kerjasama dan kolaborasi pemanfaatan algacokelat (Sargassum $\mathrm{sp})$.

3. Mendorong ekonomi kerakyatan masyarakat pesisir dalam pemanfaatan algacokelat (Sargassum sp) 


\section{METODE PELAKSANAAN}

\section{Tempat dan Waktu}

Pelaksanaan kegiatan ini telah dilaksanakan pada tanggal 20 September 2019 di Desa Lhok Bubon Kecamatan Samatiga Kabupaten Aceh Barat Propinsi Aceh (Gambar 2).

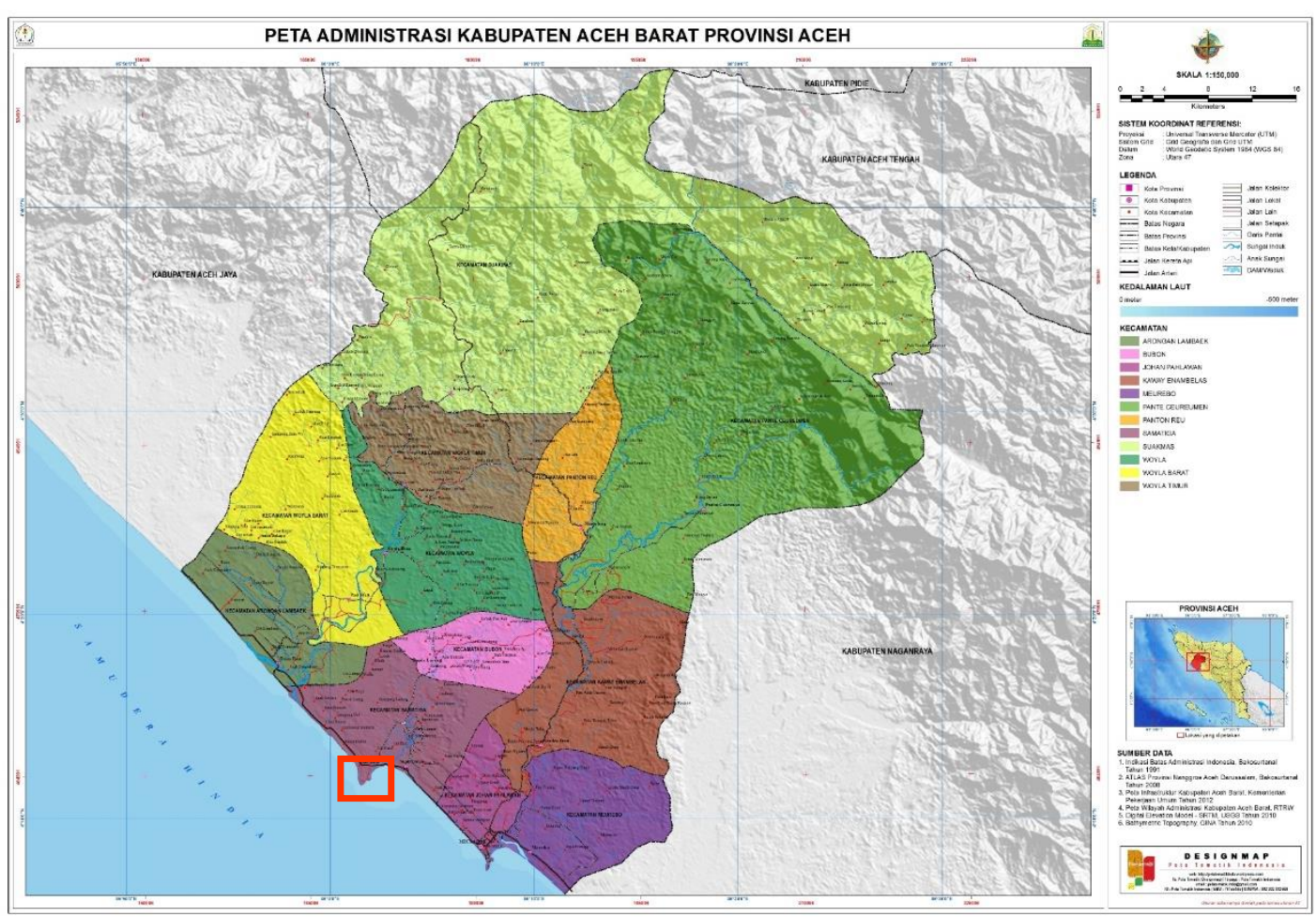

Gambar 2. Peta Lokasi Kegiatan Pengabdian kepada Masyarakat Sumber: (Peta Tematik Indonesia, 2012).

\section{Teknik Pelaksanaan}

Teknik yang digunakan dalam menyelesaikan pemasalahan masyarakat pesisir Lhok Bubon yaitu melakukan pendekatan edukasi berbasis masyarakat dengan terjun langsung di lapangan. Adapun tahapan pekerjaan dalam menyelesaikan permasalahan dan sekaligus pencapaian tujuan program adalah sebagai berikut :

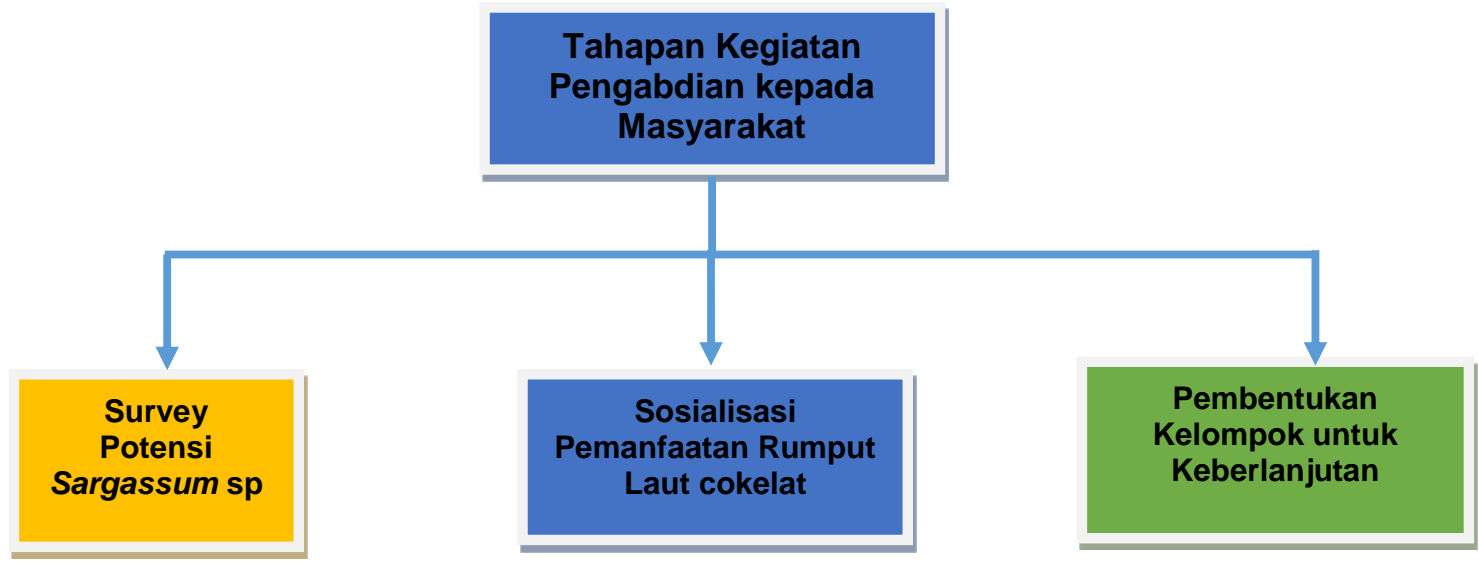

Gambar 3. Tahapan Pelaksanaan 


\section{HASIL DAN PEMBAHASAN}

\section{Survey Potensi AlgaCokelat (Sargassum sp)}

Berdasarkan hasil survey lapangan bahwa potensi algacokelat (Sargassum sp) cukup pesat yang tersedia sepanjang musim. Kami menemukan pada setiap stasiun pengamatan terdapat alga cokelat (Sargassum sp). Bahkan pada kawasan pesisir Barat Selatan (Barsela) Aceh cukup banyak tersebar algacokelat (Sargassum sp) di sepanjang pantai dengan karakteristik zona intertidal yang bervariasi pada setiap kawasan pesisir pantai (Gambar 4).

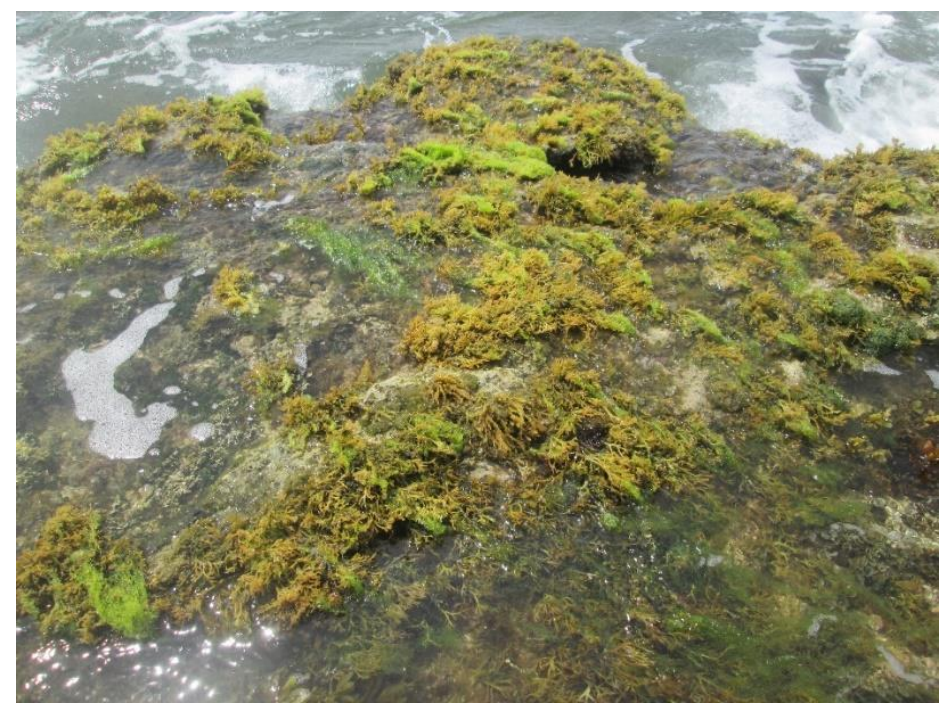

Gambar 4. Distribusi alga cokelat (Sargassum sp) pada zona Intertidal

\section{Sosialisasi Pemanfaatan AlgaCokelat (Sargassum sp)}

Peneliti bersama anggota tim melaksanakan sosialisasi pemanfaatan alga cokelat (Sargassum sp) di Pesisir Lhok Bubon. Tujuan pelaksanaan kegiatan sosialisasi ini adalah untuk meningkatkan pemahaman dan keterampilan kepada masyarakat pesisir Lhok Bubon terkait pemanfaatan algacokelat (Sargassum sp). Kami menjelaskan bahwa alga cokelat (Sargassum sp) bisa diolah sebagai teh Sargassum sp. Kami sudah melakukan penelitian terkait kandungan senyawa bioaktif (Bioactive compound) pada alga Sargassum sp yang berhubungan dengan aktivitas antioksidan. Masyarakat lokal sangat antusias mengikuti rangkaian sosialisasi dan dilanjutkan dengan pembentukan kelompok Bungong Kareung sebagai keberlanjutan program (Gambar 5).

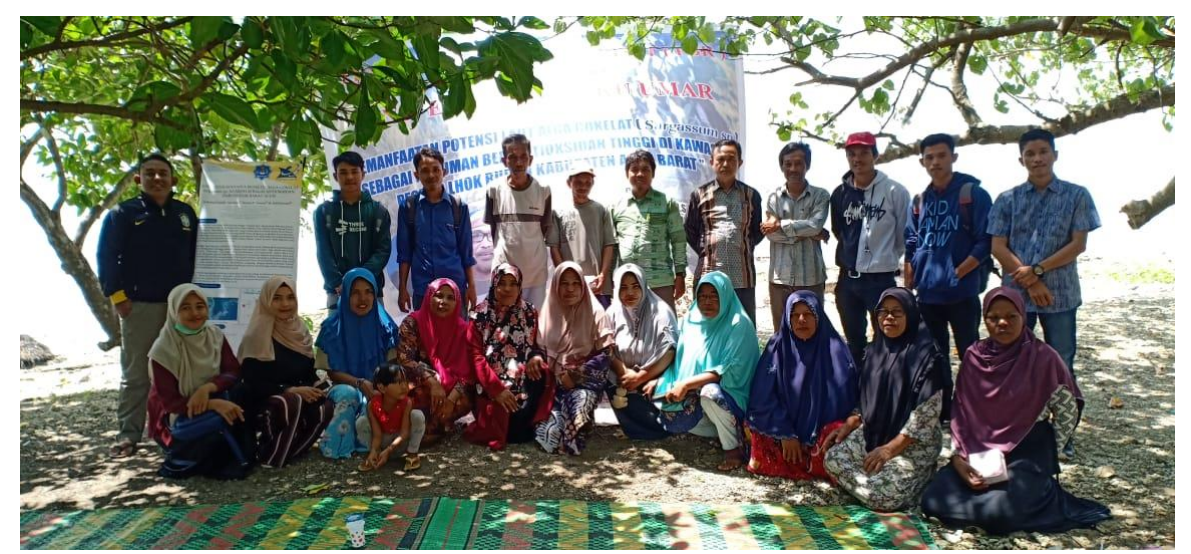

Gambar 5. Pembentukan kelompok Bungong kareung pada masyarakat Lhok Bubon 
Kegiatan sosialisasi ini merupakan bagian dari program Pengabdian Berbasis Riset (PBR) pendanaan tahun 2019 melalui hibah Universitas Teuku Umar. Outcomes pelaksanaan ini diharapkan memberikan stimulus bagi masyarakat pesisir dalam optimalisasi pemanfaatan potensi laut secara berkelanjutan. Hal ini merupakan perwujudan visi dan misi Universitas Teuku Umar sebagai sumber inspirasi dan referensi. Program Pengabdian kepada masyarakat ini merupakan salah satu unsur Tridarma Perguruan Tinggi. Oleh karena itu, kami berusaha memberikan berbagai inovasi berbasis riset kepada masyarakat pesisir Lhok Bubon. Tingkat pengangguran akan diminimalisir dengan menciptakan lapangan kerja baru bagi masyarakat lokal melalui pemanfaatan potensi sumberdaya kelautan secara berkelanjutan. Disamping itu, aspek konservasi ekosistem algajuga harus menjadi perhatian utama sehingga tidak mengalami gangguan akibat pemanfaatan alga cokelat sebagai bahan baku. Masyarakat tidak sembarang mengambil alga di pesisir dengan memotong bagian talus dengan tidak mencabut akar pada substrat. Selain itu, upaya budidaya alga cokelat (Sargassum sp) juga dijadikan skala prioritas apabila algatersebut pemanfaatannya sudah mengalami peningkatan skala industri. Berbagai produk berbasis kelautan yang dapat diproduksi melalui pemanfaatan alga cokelat (Sargassum sp) seperti pewarna alami pada mie Aceh dan teh Sargassum sp yang sudah terbukti kandungan senyawa aktif dalam alga cokelat tersebut sehingga memiliki prospek dalam bidang pangan, farmasi dan kosmetik (Gambar 6).

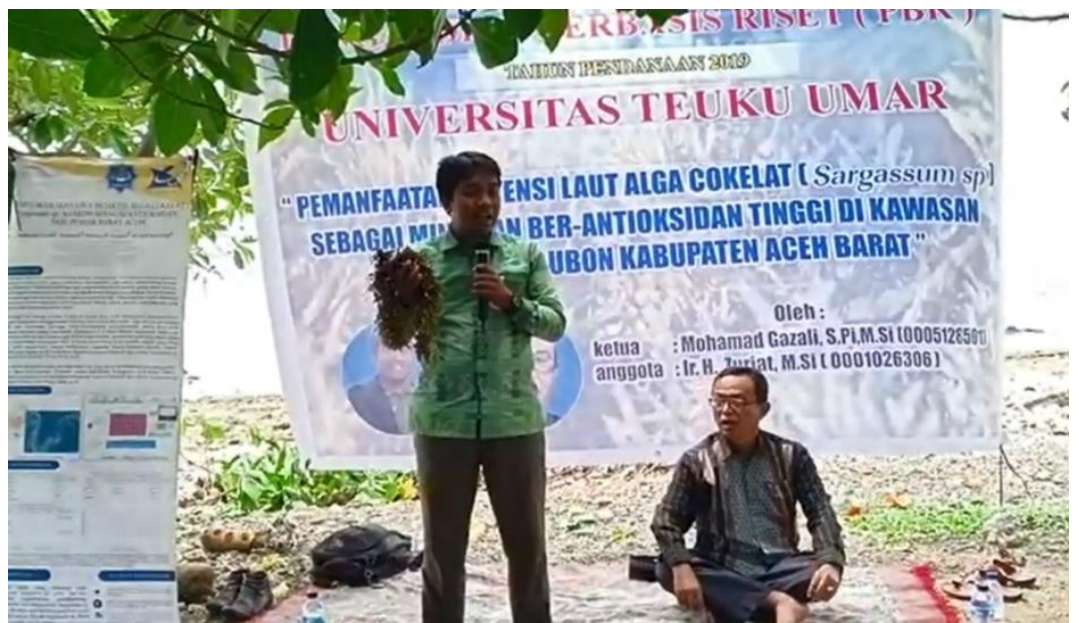

Gambar 6. Pelaksanaan Sosialisasi Pengabdian Berbasis Riset (PBR)

\section{SIMPULAN DAN SARAN Simpulan}

Berdasarkan hasil dan pembahasan di atas disimpulkan bahwa program kegiatan pengabdian kepada masyarakat ini memberikan dampak positif bagi masyarakat pesisir Lhok Bubon yaitu peningkatan pengetahuan dan keterampilan dalam hal pemanfaatan potensi laut Aceh Barat yaitu alga cokelat (Sargassum sp) sebagai marine natural product yaitu teh Sargassum sp. Kegiatan pengabdian kepada masyarakat meliputi survey lokasi potensi alga cokelat (Sargassum sp), Sosialisasi dan pembentukan kelompok masyarakat. 


\section{Saran}

Perlu adanya penguatan organisasi masyarakat lokal dalam hal pemanfaatan potensi sumberdaya kelautan secara berkelanjutan (Sustainable).

\section{UCAPAN TERIMA KASIH}

a. Dalam mensukseskan kegiatan pengabdian kepada masyarakat ini tidak terlepas dari kerjasama yang baik dari mitra program Pengabdian Berbasis Riset (PBR), Ibu Cut Sri Wahyuni yang memfasilitasi pertemuan dengan masyarakat lokal. Oleh karena itu kami mengucapkan terima kasih yang setinggi-tingginya

b. Ucapan terima kasih kepada mahasiswa Jurusan IImu Kelautan FPIK-UTU yang membantu peneliti dalam mempersiapkan kegiatan Pengabdian berbasis Riset (PBR).

\section{DAFTAR PUSTAKA}

Anonim. 2003. Teknologi pemanfaatan rumput laut. Jakarta: Pusat Riset Pengolahan Produk dan Sosial Ekonomi. Departemen Kelautan dan Perikanan.

Gazali M, N Nurjanah, NP Zamani. 2018. Eksplorasi senyawa bioaktif alga cokelat Sargassum sp. Agardh sebagai antioksidan dari Pesisir Barat Aceh. Jurnal Pengolahan Hasil Perikanan Indonesia 21 (1), 167-178

Nindyaning R. 2007. Potensi Rumput Laut.

http://www.halalguide.info/content/view/808/38/ - 27k - .

[16 Oktober 2019].

Novaczek I dan Athy A. 2001. Sea Vegetable Recipes for The Pasific Islands. Fiji Islands: Community Fisheries Training Pacific Series-3B.

Permana RA. 2008. Karakteristik serbuk minuman sari buah jeruk lemon (Citrus medica var lemon) dengan penambahan na-alginat yang diekstraksi dari rumput laut Sargassum filipendula [skripsi]. Bogor: Program Studi Teknologi Hasil Perikanan, Fakultas Perikanan dan IImu Kelautan, Institut Pertanian Bogor.

Putra, Sinly Evan. 2006. Tinjauan Kinetika dan Termodinamika Proses. Adsorpsi Ion Logam Pb, Cd, dan Cu oleh Biomassa Rumput laut Nannochloropsis sp. Yang Dilmobilisasi Polietilamina - Glutaraldehid. Laporan Penelitian. Universitas Lampung. Bandar Lampung.

Susanto AB. 2009. Potensi rumput laut Sebagai Bahan Campuran Minuman Teh. http://rumputlaut.org/tag/sargassum/. Yayasan Rumput Laut Indonesia (YRLI). [24 Maret 2010].

Winarno FG. 1996. Teknologi Pengolahan Rumput Laut. Jakarta: Pustaka Sinar Harapan.

Yorita N. 2010. Karakteristik permen jelly rumput laut Kappaphycus alvareziic dengan penambahan pati termodifikasi sebagai bahan pengisi [Jurnal]. Bogor : Departemen Teknologi hasil Perairan, Fakultas Perikanan dan IImu Kelautan, Institut Pertanian Bogor. 